\title{
Use of Propolis for Topical Treatment of Dermatophytosis in Dog
}

\author{
Tonatiuh Alejandro Cruz Sánchez' ${ }^{1}$ Perla Alejandra Estrada García1, \\ Cristian Ismael López Zamora1, Marcela Autran Martínez², Víctor Pérez Valencia², \\ Amparo Londoño Orozco ${ }^{1}$ \\ ${ }^{1}$ Facultad de Estudios Superiores Cuautitlán, Universidad Nacional Autónoma de México, Cuautitlán Izcalli, \\ México \\ ${ }^{2}$ Belén Veterinary Hospital, Tultitlan, México \\ Email: tonatiuh86@hotmail.com
}

Received 12 July 2014; revised 10 August 2014; accepted 16 September 2014

Copyright (C) 2014 by authors and Scientific Research Publishing Inc.

This work is licensed under the Creative Commons Attribution International License (CC BY). http://creativecommons.org/licenses/by/4.0/

(c) $\underset{\mathrm{EY}}{\mathrm{E}}$ Open Access

\begin{abstract}
Here we present three clinical cases of canine dermatophytosis resolved with topical propolis treatment that involved alopecia and well-demarcated erythematous lesions. These cases were positively identified by direct observation of samples from the affected zones with $10 \% \mathrm{KOH}$. Each sample was cultured, leading to the isolation of Microsporum gypseum in one case and Microsporum canis in the other two cases. The animals' subsequent treatment included bathing using a commercial soap with propolis every seven days for 3 to 8 weeks, as well as the use of a propoliscontaining ointment elaborated in our laboratory, which was applied to the lesions once a day for three weeks. From the second week of treatment, all cultures were negative. At the end of treatment, all cases displayed full recovery of the injuries and hair growth in these areas. In these clinical cases, treatment with propolis was effective, supporting the use of propolis as a promising natural alternative with no known collateral effects.
\end{abstract}

\section{Keywords}

Canine, Dermatophytosis, Microsporum, Treatment, Propolis

\section{Introduction}

Dermatophytosis (ringworm) is a superficial skin infection caused by pathogenic dermatophytes of the filamentous fungi group comprising the genera Epidermophyton, Trichophyton, and Microsporum. Dermatophytes can digest keratin, and they live on keratinized tissues, such as nails, hair follicles, hair, and the stratum corneum 
of the skin. Dermatophytes are important because they have a zoonotic potential. Diverse treatments have been proposed for this clinical disease [1] [2], including multiple antidermatophytic medications for both systemic and topical administration. However, the available antifungal agents—such as allylamine, azoles, and othersare inefficient and are associated with severe side effects. Dermatologists often attribute treatment failures to short therapy duration and lack of adequately specific drugs [3].

Efforts to develop new therapeutic strategies to treat mycosis have focused on treatments involving natural derivatives. Antifungal compounds are common in nature, with many volatile essential oils obtained from plants showing promise as suitable tools to combat mycoses in both human and animals. Among such products, propolis has recently seen increasing usage in medicine [4]. Propolis is made by bees and comprises about $50 \%$ resinous components, mostly polyphenols [5]. Its medical use has been documented over more than two millennia, and it reportedly possesses extensive pharmacological properties, including antibacterial, antifungal, antiviral, antiparasitic, antiinflammatory, antioxidant, antiulcer, hepatoprotective, antitumor, immunomodulatory, healing, and anesthetic [6] [7].

Reports of the antifungal activity of natural products, including propolis, typically correspond to in vitro tests. Studies have shown the efficacy of propolis against some dermatophytes, including Microsporum gypseum [8]. In the present study, we reported three cases of canine dermatophytosis resolved with topical propolis treatment.

\section{Material and Methods}

\subsection{Cases}

Case 1 was a two-month-old, 2.3-kg, white, male creole dog that lived in an apartment. The owner noticed alopecic areas in the left anterior member and both hind limbs. The animal was observed to lick and occasionally scratch these areas, and injuries had been noticed a week and a half earlier. No treatment had yet been administered to control these problems. Examination of the skin and annexes revealed an oval erythematous area of approximately five inches in diameter with well-defined borders and loss of hair on the skin of the left forelimb, at the height of the radiocarpal joint. The same type of lesion was also observed on the hindquarters, on the skin covering the region of the distal phalanges and in the interphalangeal space (Figure 1(a)).

Case 2 was a five-month-old, 10-kg canine of the Boxer breed, with skin lesions covering almost the entire head (Figure 2(a)). The owner had reported observing injuries to the animal several months earlier, and the animal was previously treated for scabies without success. The animal had a sloppy and dirty appearance and the third eyelid of his left eye was inflamed. The dog showed signs of malnutrition, was underweight, had no proper diet, and lived in the open, in other words, it was suffering animal abuse. The dog lived in an area where the floor was earth, and did not live with other dogs.

Case 3 was an eight-month-old male canine of the Yorkshire terrier breed. This animal had been subjected to multiple previous treatments with antibacterial ointments. Its body condition was deteriorating and it suffered from generalized pruritus. Skin problems were apparent, and on the animal's back was found a keloid scar that was circular, elevated, and of a soft consistency, corresponding to the inflammatory lesion called a Celsus kerion. (Figure 3(a)). No antimicrobials were used as secondary prophylaxis for the associated infections.

\subsection{Laboratory Procedures}

For the first case, the following tests were performed: blood count, blood chemistry of three elements (glucose, urea, creatinine) and skin scrapings that were sent to the laboratory of parasitology and mycology. In the second case, only skin scrapings were sent to the mycology lab. For the third case, skin scraping was performed, as well as a complete blood count to rule out problems associated with food-borne hypersensitivity. An intradermic test was performed to detect possible allergies to the following antigens: pollen, grass, cotton, and fiberglass.

For each mycological examination, hair samples were taken and scales were collected from the edges of the lesions for direct examination with $10 \% \mathrm{KOH}$. These samples were then used to inoculate plates containing Mycobiotic agar. After these Petri dishes were incubated at $28^{\circ} \mathrm{C}$ for one week, we observed the formation of colonies with a sandy appearance. Using Riddel's microculture technique [9], identification was performed on the morphological characteristics using the monographs of Larone [10]. For the radial growth inhibition procedure (antifungal activity assay), sterile $5 \mathrm{~mm}$ diameter discs of Whatman paper No. 5 were impregnated with 4, 8, 12 , and $16 \mathrm{mg}$ of ethanolic extract of propolis (EEP), based on a stock solution of $120 \mathrm{mg} / 300 \mu \mathrm{l}$ and another of 


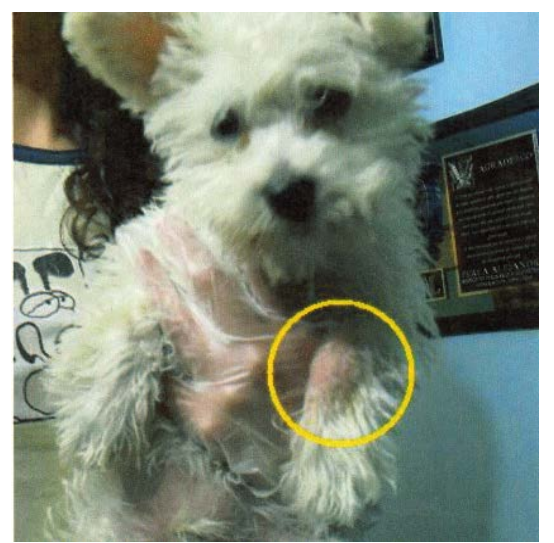

(a)

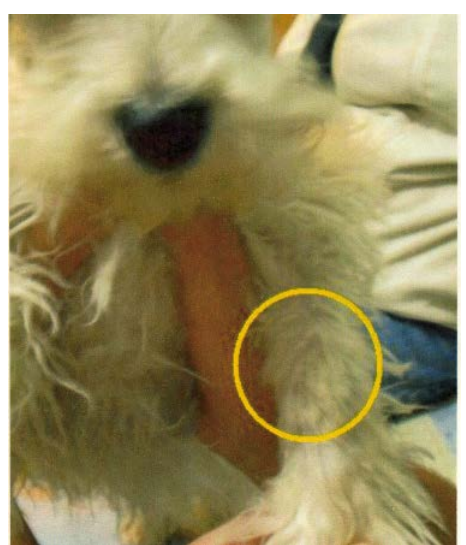

(b)

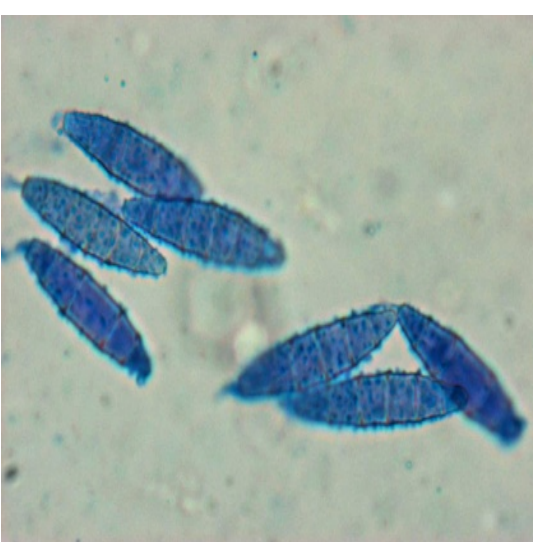

(c)

Figure 1. Case 1, Creole. (a) Alopecic lesion and erythematous left forelimb (yellow circle); (b) Left forelimb of patient without Lesion after three weeks of treatment; (c) Microsporum gyseum isolated from this clinical case (lactophenol cotton blue staining, $40 \times$ ).

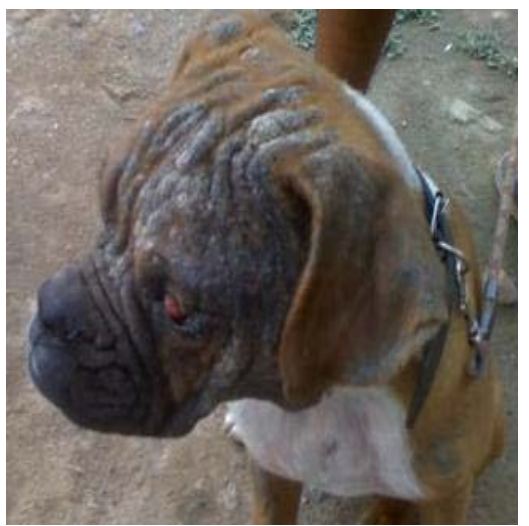

(a)

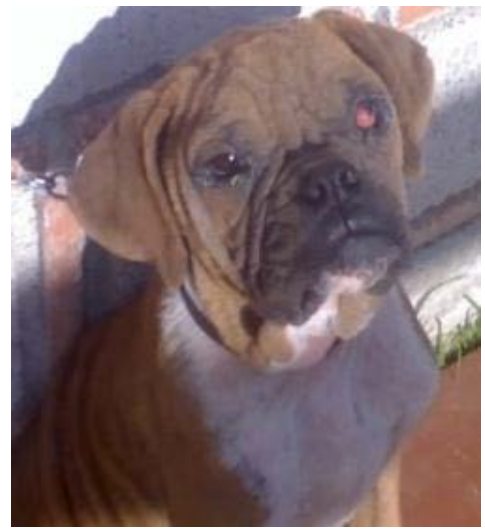

(b)

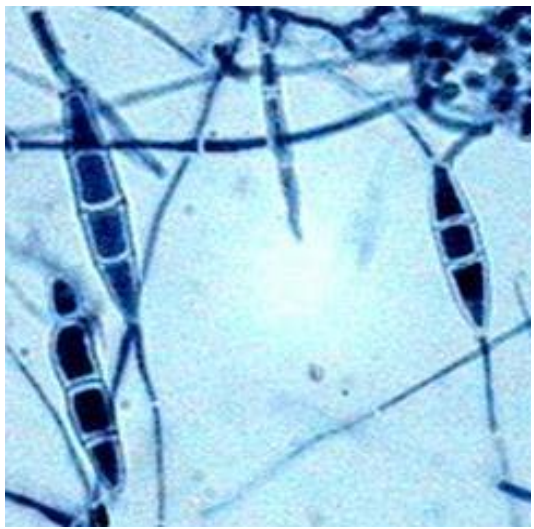

(c)

Figure 2. Case 2, Boxer. (a) Skin lesions covering almost the entire head; (b) Patient without lesion after three weeks of treat ment; (c) Microsporum canis isolated from this clinical case (lactophenol cotton blue staining, 40×).

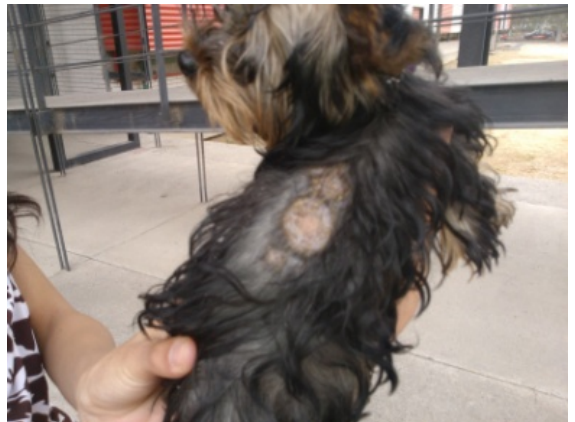

(a)

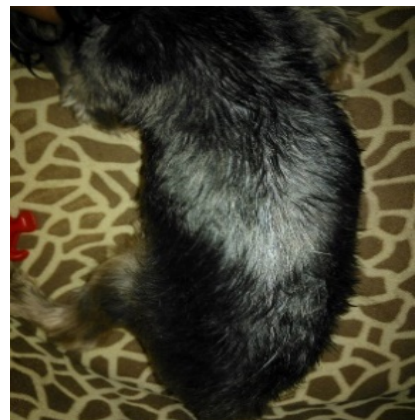

(b)

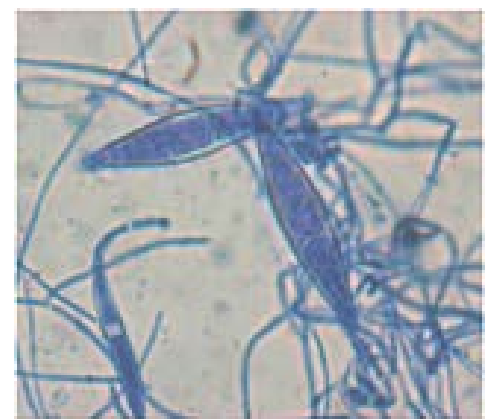

(c)

Figure 3. Case 3, Yorkshire. (a) Alopecic lesion and erthematous patches; (b) Patient without lesion after eight weeks of treatment; (c) Microsporu canis isolated from this clinical case (lactophenol cotton blue staining, 40×).

$360 \mathrm{mg} / 300 \mu \mathrm{l}$, using 70\% ethanol as the solvent. Control discs were impregnated with only $10 \mu \mathrm{l} 70 \%$ ethanol. For each examined fungi, a $5 \mathrm{~mm}$ diameter portion of culture was placed in the center of a Petri dish $(100 \times 15 \mathrm{~mm})$ containing $20 \mathrm{ml}$ of sterile potato dextrose agar (PDA, DIBICO), and discs were placed around the inoculum, maintaining a 30-mm distance from it. Control discs were impregnated with $50 \mu \mathrm{g}$ ketoconazole (BIORAD 62866) 
and $50 \mu$ g clotrimazole (BIORAD 62816). All Petri dishes were incubated at $28^{\circ} \mathrm{C}$ in the dark for 72 to 96 hours, or until the agar surface was covered by mycelium. Radial growth inhibition was observed by the formation of half-moon-shaped zones of inhibition around the discs. Each assay was repeated three times [11] [12].

To determine the minimum inhibitory concentration (MIC), we made a stock solution of $100 \mathrm{mg}$ propolis in $400 \mu \mathrm{l} 70 \%$ ethanol. From this stock solution, seven different concentrations of propolis were prepared in potato dextrose agar (PDA, DIBICO): 3.0, 2.5, 2.0, 1.5, 1.0, 0.50, and $0.25 \mathrm{mg} / \mathrm{ml}$. Using 24-well flat-bottom plates (EVERGREEN), we added $1 \mathrm{ml}$ PDA to each well, including a specific concentration of propolis. We prepared three wells with each concentration, as well as with controls that included PDA without extract. After the sterility test, the center of each well was inoculated with a 1.6-mm-diameter fragment of the fungus culture. The plates were incubated at $25^{\circ} \mathrm{C}$ for 7 days until the total development of the controls without propolis. The minimum inhibitory concentration (MIC) was considered to be the lowest concentration of propolis that inhibited the growth of each tested fungus [12] [13].

\subsection{Treatment}

Lesions were washed daily with commercial soap containing propolis (Protex with propolis, COLGATE) for three weeks. Propolis ointment was made at our laboratory using a propolis sample collected in the apiary of the Faculty. EEP was obtained by maceration of $30 \mathrm{~g}$ propolis in $100 \mathrm{~mL} 70 \%$ ethanol for one week at room temperature. After filtration, the extract was evaporated under vacuum at $50^{\circ} \mathrm{C}$. The propolis extract $(5 \mathrm{~g})$ was heated in a water bath with 30 g petroleumjelly (Vaseline) until melting. They were then mixed, and this mixture was used as the propolis ointment for application to the dogs. By HPLC analysis, the main propolis constituents had previously been identified as flavones, cinnamic acid derivative, and caffeic acid derivative [14]. The ointment was applied once daily to the carefully washed and dried lesions, for three weeks for cases 1 and 2 and eight weeks for case 3 . The patients were bathed with the same commercial soap with propolis every seven days for three weeks, and the skin was thoroughly dried after each bath. For case 2, in addition to the treatment, the patient was supplied with a vitamin complex and commercial food. No other pharmaceutical product was applied. A hair sample was taken every week to detect the presence of dermatophytes.

\section{Results}

In case 1, hematic biometry revealed absolute lymphocytosis, neutropenia and monocytopenia. Blood chemistry showed glucose levels high, urea normal and creatinine levels below. The skin scrapings were negative for the presence of parasites. In case 3, hematic biometry showed that the blood was normal, and intradermal tests were negative.

From all cases, hair samples were evaluated by direct observation with $10 \% \mathrm{KOH}$, which revealed an ectothrix type of parasitism. The fungal isolate from case 1 was identified as Microsporum gypseum, while those from cases 2 and 3 were identified as Microsporum canis (Figure 1(c), Figure 2(c), and Figure 3(c)). The radial growth inhibition assay showed that the two strains of $M$. canis were inhibited at all concentrations, while $M$. gypseum was inhibited only at 2, 4, and $8 \mathrm{mg}$ (Figure 4). For all three strains, the MIC was determined to be 0.5 $\mathrm{mg} / \mathrm{ml}$.

All cases were reviewed every seven days from the third week of treatment. For cases 1 and 2, remission of all lesions and hair growth in the affected areas were observed at the end of three weeks of treatment. Case 3 presented positive results from the first week-including significant reduction of pruritus, increased feed intake, and increased tolerance to ointment application —and the lesion resolution occurred progressively from the 3rd week to the final resolution after 8 weeks. Negative cultures were obtained from all cases at the third week of treatment (Table 1 \& Figure 1(b), Figure 2(b), Figure 3(b)).

\section{Discussion and Conclusion}

Several studies have examined the in vitro antimycotic activity of propolis against dermatophytes, but reports of clinical case studies are scarce. In one study performed in humans, the efficacy of two weeks of topical application of $100 \mathrm{mg} / \mathrm{ml}$ Brazilian propolis was demonstrated in seven patients with varying degrees of tinea corporis and tinea interdigitalis from which Trichophyton rubrum was isolated [15]. Propolis has also shown clinical efficacy against chronic vaginal candidiasis. Among 54 patients with recurrent vaginal infections who had under- 


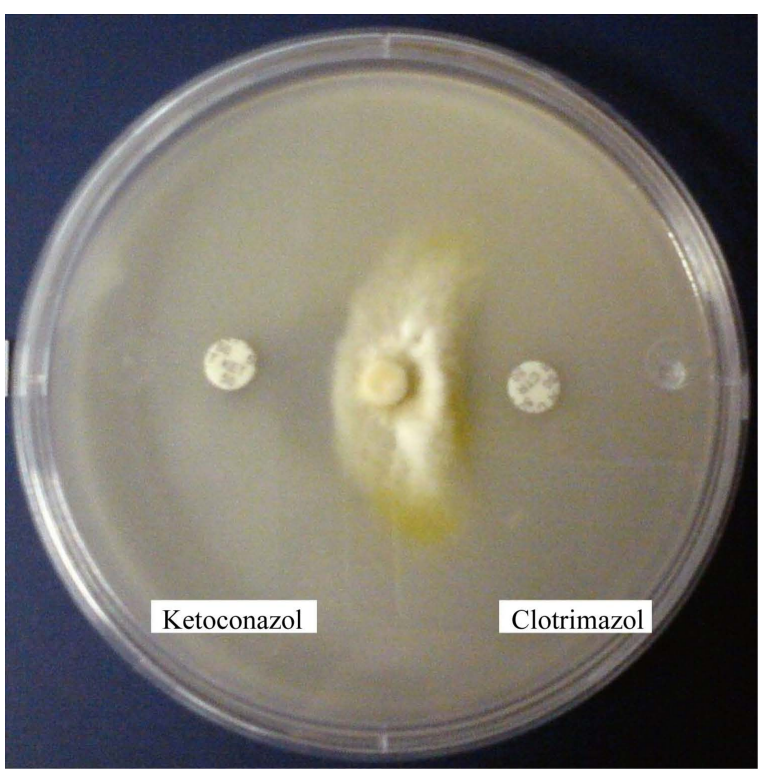

(a)

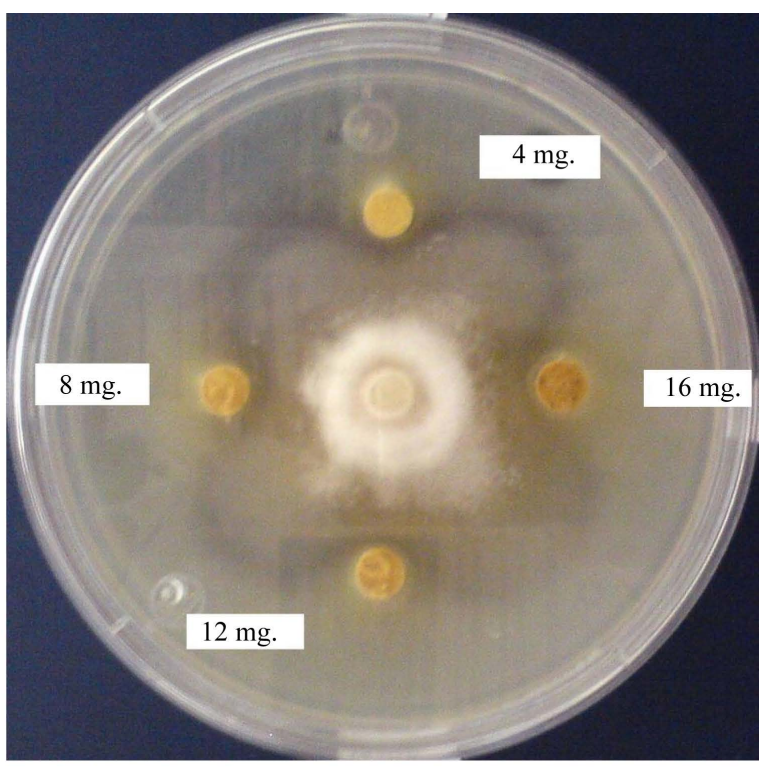

(b)

Figure 4. Radial growth inhibition. $M$. canis in potato dextrose agar. Inhibition produced with control discs (a) and with discs impregnated with 4, 8, 12, and 16 mg EEP (b).

Table 1. Summary of clinical cases of canine dermatophytosis treated with propolis.

\begin{tabular}{cccccc}
\hline Case & Breed & $\begin{array}{c}\text { Age } \\
\text { (months) }\end{array}$ & Sex & Lesion localization & $\begin{array}{c}\text { Dermatophyte } \\
\text { Isolated }\end{array}$ \\
\hline 1 & Creole & 2 & Male & $\begin{array}{c}\text { Left forelimb, at the height of the } \\
\text { radiocarpal joint. }\end{array}$ & Microsporum gypseum \\
2 & Boxer & 5 & Male & Head & Microsporum canis \\
3 & $\begin{array}{c}\text { Yorkshire } \\
\text { terrier }\end{array}$ & 8 & Male & $\begin{array}{c}\text { Back, corresponding to an inflammatory } \\
\text { lesion identified as Celsus kerion }\end{array}$ & Microsporum canis \\
\hline
\end{tabular}

gone at least one cycle of antibiotic treatment, application of a 5\% aqueous propolis solution as a vaginal douche for seven days was demonstrated to be an effective treatment [5]. Propolis has also been clinically tested for use against epidermophytosis in tuberculosis skin lesions, alopecia, psoriasis by various microorganisms, chronic eczema, pyoderma, and stigmatizing injuries infected with Trichophyton in human patients [6].

Additionally, propolis has been shown to be effective in the treatment of oral diseases in humans. One study showed that EEP inhibited all of the Candida albicans strains collected from HIV-seropositive and HIV-seronegative Brazilian patients with oral candidiasis. The effects of EEP did not significantly differ from those of nystatin, but did significantly differ from the effects of other antifungals, since $C$. albicans showed resistance to antifungal agents. Brazilian commercial EEP formulated to ensure physical and chemical stability was also found to inhibit oral candidiasis in 12 denture-bearing patients with prosthesis-associated stomatitis and candidiasis. The available data suggest that commercial EEP could be an alternative medicine for candidiasis treatment in HIV-positive patients [16].

With regard to veterinary medicine, propolis is reportedly active against fungal otitis in dogs. In one study, a propolis preparation was administered to the external ear canals, twice daily for 14 days. Of the 38 dogs treated with propolis, 27 (71\%) responded satisfactorily (i.e., cured or clearly improved, both clinical and microbiologically). The remaining 11 dogs (29\%) did not respond to the treatment and were thus treated with a different therapy after the trials. These findings support the interest in developing a topical formulation of propolis as a promising new therapy for the treatment of otitis in dogs, as it appears that this formulation has a wide antimicrobiological spectrum, antiinflammatory effects, and is a natural and inexpensive product [17].

Another veterinary study determined that the application of propolis and Whitfield's ointment was a highly effective treatment for bovine dermatophytosis, showing results better than with the use of either substance alone. However, this study involved topical treatments applied over a period of 14 days, and thus this treatment 
might not be practical in cases where large areas of skin are affected, in modern husbandry systems involving many animals, and in countries where production costs are high [18].

The present study provides the first information regarding propolis use in canine dermatophytosis or ringworm. Our preliminary data suggest a possible application of propolis for the treatment of dermatomycosis in dogs. Considering the potential zoonotic impact, the use of alternative antimycotic compounds would be of aid to limit the development of Microsporum canis and M. gypseum infections.

\section{Acknowledgements}

The authors express their gratitude to the UNAM DGAPA projects PAPIIT IT223811-3 and FESC PIAPIC28.

\section{References}

[1] Del Palacio, A., Garau, M. and Cuétara, M. (2002) Tratamiento actual de las dermatofitosis. Revista Iberoamericana de Micología Médica, 19, 68-71. www.reviberoammicol.com/2002-19/068071.pdf

[2] García, P., Ruiz, J., García, L. and Linares, M. (2004) Dermatofitosis por Microsporum gypseum. Descripción de Ocho casos y revisión de la literatura. Revista Iberoamericana de Micología Médica, 21, 147-149. www.reviberoammicol.com/2004-21/147149.pdf

[3] Yehia, A. and Mahmoud, G. (2003) In Vitro Evaluation of Antidermatophytic Activity of Egyptian Bee Propolis in Combination with Plant Essential Oils in Sheep Hoof Plate: An Experimental Model. Mycobiology, 31, 99-104. http://dx.doi.org/10.4489/MYCO.2003.31.2.099

[4] Mugnaini, L.A., Nardoni, A., Pintoa, L., Pistelli, B., Leonardi, M.B. and Pisseri, F. (2012) In Vitro and in Vivo Antifungal Activity of Some Essential Oils against Feline Isolates of Microsporum canis. Journal of Micology Medicine, 22, 179-184. http://dx.doi.org/10.1016/j.mycmed.2012.04.003

[5] Imhof, T.M., Lipovac, M., Kurz, Ch., Barta, M., Verhoeven, H.C. and Huber, J.C. (2005) Propolis Solution for the Treatment of Chronic Vaginitis. International Journal of Gynecology and Obstetrics, 89, 127-132. http://dx.doi.org/10.1016/j.ijgo.2005.01.033

[6] Bogdanov, S. (2012) Propolis: Composition, Health, Medicine: A Review. http://www.bee-hexagon.net/files/file/fileE/Health/PropolisBookReview.pdf

[7] De Castro, S.L. (2001) Propolis: Biological and Pharmacological Activities Therapeutic Uses of This Bee-Product. Annual Review of Biomedical, 3, 49-83. http://132.248.9.34/hevila/ARBSAnnualreviewofbiomedicalsciences/2001/vol3/2.pdf

[8] Agüero, M.B., Gonzalez, M., Lima, B., Svetaz, L., Sánchez, M., Zacchino, S., Feresin, G.E., Schmeda-Hirschmann, G., Palermo, J., Wunderlin, D. and Tapia, A. (2010) Argentinean Propolis from Zuccagnia punctata Cav. (Caesalpinieae) Exudates: Phytochemical Characterization and Antifungal Activity. Journal of Agricultural and Food Chemistry, 58, 194-201. http://dx.doi.org/10.1021/jf902991t

[9] Koneman, E.W. (2008) Microbiological Diagnosis Text and Color Atlas Ed. Médica Panamericana. Mèxico, 11141115.

[10] Larone, D.H. (2011) Medically Important Fungi: A Guide to Identification. ASM Press, Washington DC.

[11] Phongpaichit, S., Subhadhirasakul, S. and Wattanapiromsakul, Ch. (2005) Antifungal Activities of Extracts from Thai Medicinal Plants against Opportunistic Fungal Pathogens Associated with AIDS Patients. Mycoses, 48, 333-338. http://dx.doi.org/10.1111/j.1439-0507.2005.01142.x

[12] Ye, X.Y., Wang, H. and Ng, T.B. (1999) First Chromatographic Isolation of an Antifungal Thaumatin-Like Protein from French Bean Legumes and Demonstration of Its Antifungal Activity. Biochemical and Biophysical Research Communications, 263, 130-134.

[13] Wang, H. and Ng, T.B. (2002) Isolation of an Antifungal Thaumatin-Like Protein from Kiwi Fruits. Phytochemistry, 61, 1-6. http://dx.doi.org/10.1016/S0031-9422(02)00144-9

[14] Londoño, A., Canales, M., Hernández, T.,Ávila, G., Serrano, R., Penieres, J.G., García, C.G., Cruz T.A., et al. (2010) Antibacterial Comparative Study between Extracts of Mexican Propolis and of Three Plants Which Use Apis mellifera for Its Production. Journal of Animal and Veterinary Advances, 9, 1250-1254. http://dx.doi.org/10.3923/javaa.2010.1250.1254

[15] Ngatu, N.R., Saruta, T., Hirota, R., Eitoku, M., Severin, L.N., Andre, M.B., Matsui, T. and Suganuma, N. (2012) Brazilian Green Propolis Extracts Improve Tinea pedis interdigitalis and Tinea corporis. Journal of Alternative and Complementary Medicine, 18, 8-9. http://dx.doi.org/10.1089/acm.2011.0696

[16] Rodrigues Santos, V. (2012) Propolis: Alternative Medicine for the Treatment of Oral Microbial. In: Sakagami, H., Ed., 
Diseases in Alternative Medicine, InTech, 134-169.

[17] Lozina, L.A., Peichoto, M.E., Boehringer, S.I., Koscinczuk, P., Granero, G.E. and Acosta, O.C. (2010) Efficacy of Argentine Propolis Formulation for Topical Treatment of Canine Otitis Extern. Arquivo Brasileiro de Medicina Veterinária e Zootecnia, 62, 1359-1366. http://dx.doi.org/10.1590/S0102-09352010000600010

[18] Cam, Y., Koç, A.N., Silici, S., Günes, V., Buldu, H., Onmaz, A.C. and Kasap, F.F. (2009) Treatment of Dermatophytosis in Young Cattle with Propolis and Whitfield's Ointment. Veterinary Record, 165, 57-58. 
Scientific Research Publishing (SCIRP) is one of the largest Open Access journal publishers. It is currently publishing more than 200 open access, online, peer-reviewed journals covering a wide range of academic disciplines. SCIRP serves the worldwide academic communities and contributes to the progress and application of science with its publication.

Other selected journals from SCIRP are listed as below. Submit your manuscript to us via either submit@scirp.org or Online Submission Portal.
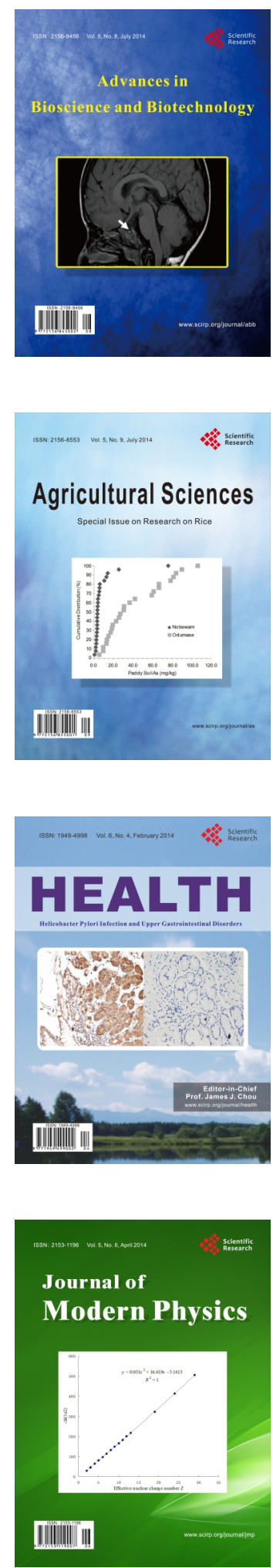
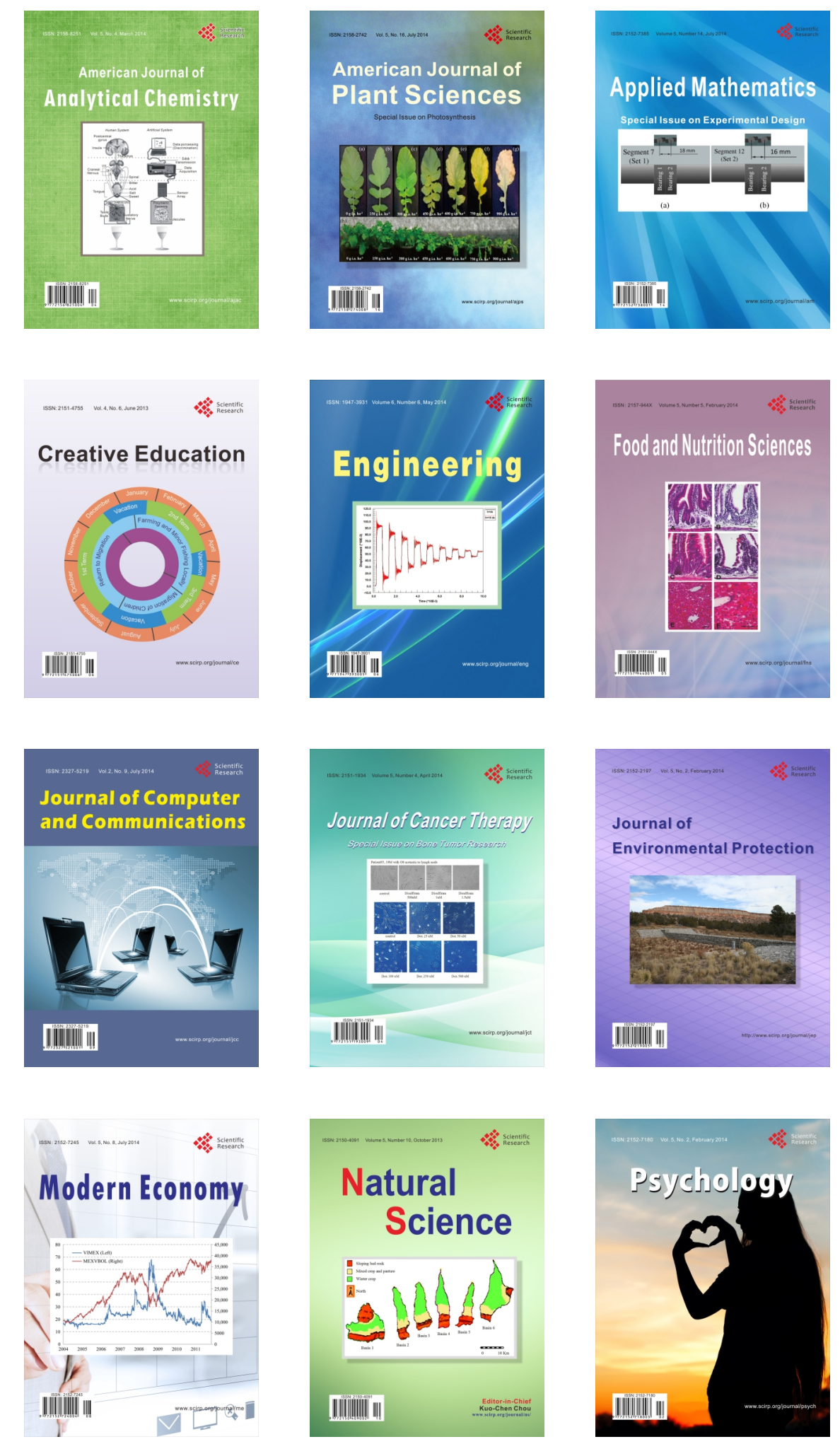